\title{
As relações de gênero na produção capitalista do espaço de trabalho*
}

\author{
Viviane Zerlotini da Silva**
}

\section{Resumo}

Este artigo discute o contexto social que originou o espaço de trabalho, ou o espaço exclusivo para o desempenho de atividades produtivistas. O objetivo é demonstrar a dependência que a esfera da produção tem do universo da reprodução e, notadamente, como essa dependência é obliterada e reforçada pelas relações patriarcais. Investigo como o processo de trabalho e a sociedade são organizados segundo as teorias de organização racional do trabalho, e quais os efeitos sobre a produção do espaço. A discussão sobre as origens dos espaços de trabalho demonstrou que elas estão vinculadas à divisão do trabalho em gênero, durante o desenvolvimento do capitalismo comercial, no período entre os séculos XII e XVIII, quando as antigas unidades domésticas - indústrias domésticas rurais - $e$ as oficinas dos artesãos urbanos foram transformadas em empresas familiares pelo modo de produção putting-out system. Com o advento desse sistema, a divisão do trabalho em gênero permitiu liberar os indivíduos do sexo masculino para o desempenho de atividades produtivas, enquanto as tarefas domésticas ou mal pagas eram destinadas às mulheres. Essa foi a primeira condição social para posteriormente, na manufatura, possibilitar-se a existência de espaços exclusivos de produção.

Palavras-chave: Precedência da Reprodução, Espaço de Trabalho, Divisão de Trabalho em Gênero.

" Recebido em 06 de agosto de 2014, aceito em 09 de novembro de 2018.

** Professora titular do curso de Arquitetura e Urbanismo da Pontifícia Universidade Católica de Minas Gerais, Belo Horizonte, MG, Brasil. zerlotini@oi.com.br / https://orcid.org/0000-0002-9738-8886 
Gender Relations in the Capitalist Production of the Workplace

\begin{abstract}
This article discusses the social context that gave origin to the workplace, or the exclusive space for the performance of productive activities. The objective is to demonstrate the dependence that the production sphere has on the universe of reproduction and especially how this dependence is obliterated and reinforced by patriarchal relations. I investigate how the labor process and society are organized according to theories of rational organization of labor, and the effects of this on the production of space. The discussion about the origins of workplaces demonstrated that they are linked to the gender division of labor, during the development of commercial capitalism between the twelfth and eighteenth centuries, when old household units - rural household industries - and urban craft workshops were transformed into family businesses by the putting-out system. With the advent of this system, the gender division of labor freed up males for productive activities, while domestic or underpaid tasks were left to women. This was the first social condition that later, in manufacturing, allowed the existence of exclusive production spaces.
\end{abstract}

Keywords: Precedence to Reproduction, Workplace, Gender Division of Labor. 
Em A Ética Protestante e o Espírito do Capitalismo, Max Weber observa que, além dos fundamentos dogmáticos e das sanções religiosas presentes na ascese puritana, há duas condições indispensáveis à moderna organização capitalista racional do trabalho livre. Uma delas é "a separação espacial entre os locais de trabalho e os de residência"; a outra é a "contabilidade racional" ou o cálculo preciso de recursos e excedentes, possível apenas a partir dessa separação (Weber, 2001:7). Embora o interesse de Weber seja a relação entre ética protestante e a "habilidade e disposição do homem em adotar certos tipos de conduta racional prática" (Weber, 2001:9), sua premissa de separação espacial entre produção e reprodução fornece um bom argumento para analisar o surgimento dos modernos espaços de trabalho a partir dessa relação, em vez de considerá-los somente a partir das categorias de análise próprias do universo da produção.

Nem toda produção orientada para o mercado demanda espaços exclusivos. Houve - e há até hoje - tanto situações de concentração de trabalhadores em fábricas, quanto situações de dispersão da produção, realizada pelos trabalhadores no ambiente doméstico. Este artigo destina-se a analisar e discutir esses diferentes tipos de espaço de trabalho, partindo de três sistemas: o artesanal, o chamado putting-oute o fabril. Trata-se de esclarecer, em cada um desses tipos, as condições de surgimento, as relações entre as atividades de produção e reprodução, as relações de gênero, a função do espaço e dos aparatos e os recursos técnicos e organizacionais. Recorrerei a exemplos históricos, mas sem pretender nenhuma abrangência nesse sentido, já que o propósito desta análise é apenas fornecer elementos para melhor compreender as especificidades dos espaços de trabalho.

$\mathrm{O}$ trabalho de reprodução visa ao valor de uso, enquanto o trabalho de produção, ao valor de troca $e$ - na produção capitalista - à mais-valia. Mas atividades de reprodução não são menos "trabalhosas" do que as de produção. Nesse sentido, a expressão espaços de trabalho deveria abranger quaisquer lugares de transformação de matéria-prima mediante o dispêndio de energia humana, independentemente de sua finalidade. Por uma 
questão de coesão, a expressão é qualificada neste texto seguida da natureza das atividades de trabalho, como espaços de trabalho de reprodução ou de produção, quando os espaços são exclusivos; e o espaço de trabalho combinado, quando o espaço de trabalho de reprodução está mesclado com o de produção.

Mas o que distingue reprodução e produção? A existência de qualquer sociedade humana, capitalista ou não, pressupõe o trabalho de reprodução ou o conjunto de operações diárias realizadas em prol da sobrevivência dos seres humanos:

Reprodução é a produção para a permanência de
determinado estado de coisas, a começar pela subsistência
orgânica dos indivíduos e pela subsistência da espécie,
mediante a procriação. Essas são as bases e condições de
possibilidade de qualquer sociedade humana. Sem
reprodução, não há produção, pois ela não teria objeto,
nem teria quem a realizasse [...] Portanto, a reprodução
tem precedência lógica sobre a produção, ainda que, do
ponto de vista gramatical, isso pareça estranho (Kapp; Lino,
2008:13).

Contudo, numa sociedade capitalista, o universo da reprodução da vida humana passa a ser determinado pelo universo da reprodução (ampliada) do capital, à qual se dá o nome de produção. Do ponto de vista do capital, apenas o trabalho que contribui diretamente para a sua acumulação é denominado "produtivo":

No processo de produção absorve-se mais trabalho do que foi comprado, e essa absorção, apropriação de trabalho alheio não pago, consumada no processo de produção, é o objetivo direto do processo de produção capitalista; pois, o que o capital quer produzir como capital (portanto, o capitalista como capitalista) não é valor de uso imediato para o próprio consumo pessoal, nem mercadoria para transformar primeiro em dinheiro e depois em valor de uso. Seu objetivo é o enriquecimento, o acréscimo do valor, seu aumento, isto é, a conservação do valor antigo e a criação 
de mais-valia. E o capital só alcança esse produto específico do processo de produção capitalista, na troca pelo trabalho, que se chama por isso de trabalho produtivo (Marx, 1987:394).

O capitalismo separou vida e trabalho em duas esferas distintas e inverteu, prática e ideologicamente, as prioridades, de uma forma "irracional de um ponto de vista ingênuo" e "que soa estranha para todas as pessoas que não estão sob a influência capitalista" (Weber, 2001:51). A precedência da produção sobre a reprodução determina que a base de valor para as atividades desempenhadas pelos seres humanos seja o trabalho produtivo, gerador de riqueza para o capitalista. Essa precedência, em bases capitalistas, é paradoxal. O trabalho de produção domina o de reprodução e, ao mesmo tempo, o trabalho de reprodução sustenta o de produção. "Fato é que o modo de produção capitalista industrial não seria capaz de prover sua própria reprodução se não contasse com essa parcela imensa de sobretrabalho" (Kapp; Lino, 2008:14). Outra característica do trabalho de reprodução refere-se à dualidade de sua mercantilização. Há uma diferença entre "porção de trabalho de reprodução que é passível de substituição por mercadorias e a porção desse trabalho que não o é" (Kapp; Lino, 2008:16). No primeiro caso, as atividades produtivas submetem-se ao planejamento pelo Estado ou pelo capital privado mediante o interesse pela acumulação. No segundo caso, as atividades que não são acumuláveis, evidentemente, não são submetidas a controle com o objetivo de crescimento linear.

Efetivamente, o trabalho de reprodução não é acumulável. À revelia do aspirador de pó, do freezer, da inseminação artificial e de toda a imensa produção de mercadorias destinadas ao consumo doméstico, não se pode limpar a poeira de amanhã, nem matar a fome da semana que vem ou gestar os filhos da década seguinte. Se o aumento das forças produtivas de uma sociedade tende a reduzir o trabalho necessário à reprodução, ainda assim uma grande 
parcela desse trabalho não pode ser mercantilizada, racionalizada ou socializada. Mesmo que muitas mercadorias estejam disponíveis e os salários efetivamente permitam comprá-las, a criação dos filhos, a manutenção da moradia, o cuidado com os doentes e até mesmo o consumo concreto envolvem um trabalho não reificável, sem o qual nenhum outro tipo de trabalho seria possível (Kapp; Lino, 2008:18).

Quanto ao tema apontado por Webber (2001), a moderna organização racional do trabalho livre, a massa de trabalhadores ditos livres constitui um elemento indispensável ao capitalismo industrial (Marx, 2010). Mas são trabalhadores livres de quê? De suas antigas relações de servidão, certamente, mas de suas antigas relações de reprodução, que incluem o acesso à terra (Marx, 1975). A condição de homem - ser humano do sexo masculino - que pode (ou melhor, precisa) vender sua força de trabalho ao capital pressupõe a separação de produção e reprodução. Apenas assim os trabalhadores podem ser reunidos pelo capitalista num mesmo local e submetidos ao seu controle direto, satisfazendo a exigência de cálculos certeiros do investimento em capital fixo que, para Weber (2001), distingue empreendimentos do capitalismo comercial de empreendimentos do capitalismo industrial. Se "tempo é dinheiro", é preciso apartar as atividades de produção de quaisquer outras.

$\mathrm{Na}$ visão de Weber, a transição do capitalismo comercial para o industrial fundamenta-se, portanto, na dissociação da vida em duas esferas distintas, de reprodução e de produção. O espaço de trabalho que primeiro realiza essa dissociação completamente está inserido na moderna manufatura. Mas é importante perceber que a transição abrange dois aspectos ou fases: de um lado, a separação entre trabalhos de produção e reprodução, a qual se concretiza na transição do sistema de produção artesanal para o sistema putting-out; do outro, a reunião de trabalhadores assalariados num mesmo local, o que se concretiza na transição do sistema putting-out para o sistema de fábrica (Kriedte; Medick; Schlumbohm, 1981). Esta última condição foi amplamente discutida 
por Marx (2010), a partir da cooperação simples, da manufatura $e$ da maquinaria, bem como por diversos outros autores (por exemplo, Decca, 1982; Marglin, 1996). No entanto, poucos estudiosos dedicaram-se à compreensão da primeira condição, cuja origem está no sistema putting-out, e não na implantação das grandes fábricas.

\section{Da produção artesanal doméstica à produção artesanal capitalista no espaço doméstico}

A produção doméstica para o mercado externo - e não somente para o autossustento ou para o mercado local - expandese muito em áreas rurais e urbanas de várias regiões da Europa, entre os séculos XVI e XIX. As denominadas "indústrias domésticas rurais" funcionam ao lado da agricultura, uma vez que a natureza sazonal da produção agrária libera a população rural para trabalhar em outras atividades na entressafra. Mesmo sem tecnologias avançadas, concentração de trabalhadores dentro de fábricas e submissão a um capitalista, essa população chega a produzir em grande escala para mercados distantes (Ogilvie; Cerman, 1996), por isso a denominação de "indústrias". Mendels (1972) chama esse período de expansão da indústria caseira de "protoindustrialização", entendendo-o como a fase que precede a indústria fabril e gera as condições para a sua implantação: o trabalho, o capital, a agricultura comercial e os mercados de consumo suprarregionais. De qualquer forma, é evidente que a produção orientada ao mercado não era exclusividade das oficinas domésticas rurais, existindo também em áreas urbanas.

As oficinas domésticas, rurais e urbanas, têm por característica, além da base tecnológica artesanal, o forte entrelaçamento com a vida familiar. $\mathrm{O}$ controle de produção $e$ consumo estava sob o domínio da família, configurando o que Medick (1981) chama de economia familiar: a formação socioeconômica que organiza e compatibiliza as esferas de produção, consumo e reprodução, por intermédio de relações comuns de trabalho de todos os membros da família. À diferença 
do moderno sistema nuclear (casal e filhos), formalizado pela instituição do casamento, essa antiga família consistia na associação entre dois grupos de parentesco que criavam vínculos, agregando terras, estatutos e descendentes. Tal associação, bem mais ampla, possibilitou o fortalecimento do regime de subsistência $e$, consequentemente, a capacidade de os camponeses resistirem às demandas de reis e nobres (Illich, 1982). E no contexto urbano, a família dos artesãos agregava, além dos parentes de sangue, os trabalhadores industriais e domésticos (Mumford, 1998).

A organização $e$ a divisão das atividades nessas famílias extensas dava-se por sexo e idade. A literatura europeia da época indica a variedade de tarefas exercidas por cada membro da familia. Fontes inglesas e francesas, por exemplo, mostram que crianças de ambos os sexos executavam serviços domésticos, como cuidar dos animais e auxiliar na colheita (Tilly; Scott, 1987). Nas áreas rurais, mulheres jovens dedicavam-se à produção de leite, às criações e à produção de tecidos e roupas. Nas cidades, elas auxiliavam os artesãos na produção de seda, lã, sapatos, casacos, facas e outras mercadorias. Filhas e filhos, ao acompanharem os pais, adquiriam as habilidades técnicas, agrícolas e domésticas necessárias na fase adulta. O desempenho de tarefas de reprodução $e$ de produção era motivado simplesmente pela ideia de que cada novo membro da família deveria contribuir para a subsistência do grupo, assim que a idade permitisse (Tilly; Scott, 1987).

Outro aspecto importante da organização dessa economia familiar é sua relativa autonomia. Ela não tem o sentido de independência individual - noção socialmente construída pelo liberalismo -, nem tampouco de simples autossuficiência material. A autonomia consiste no direito e na capacidade de autogoverno que, no caso, aplica-se ao grupo familiar. O direito de autogoverno da unidade doméstica nunca foi reconhecido pela classe feudal, mas, na prática, as inconsistências territoriais do feudalismo abriam espaço para isso, mesmo nas áreas rurais. 
A divisão feudal das soberanias em zonas particularizadas, com limites justapostos e nenhum centro universal de competência, sempre havia permitido a existência de entidades corporativas "alógenas" em seus interstícios. Assim, embora a classe feudal tentasse por vezes reforçar a regra do nulle terre sans seigneur, isto na prática jamais foi realizado em nenhuma formação social feudal: as terras comunais - pastos, campos, florestas - e alódios disseminados permaneceram sempre um setor significativo da autonomia e resistência camponesa, com importantes consequências para a produtividade agrária total (Anderson, 1991:144).

Marx também considera a (relativa) autonomia da unidade doméstica como uma das condições de existência das antigas indústrias caseiras (Marx, 2010) e, nas áreas rurais, atribui-lhes características de uma "autarquia quase completa", que "não depende do mercado, nem dos movimentos da produção e da história dos segmentos sociais situados fora de sua esfera" (Marx, 2010:1054). Mesmo na esfera da circulação, quando o camponês ou o artesão vende ou compra produtos no mercado externo, onde o dinheiro já é meio de expressão do valor, a reprodução precede a produção. "A circulação simples de mercadoria vender para comprar - serve de meio a um fim situado fora da circulação, a apropriação de valores-de-uso, a satisfação das necessidades" (Marx, 2010:182).

É preciso compreender o antigo padrão doméstico de organização do espaço nesse contexto de "economia natural" (Marx, 2010), em que a reprodução precede as atividades produtivas e a moradia da família abriga todo tipo de atividades conjuntamente. Tanto a oficina das áreas urbanas - o workshop dos artesãos, quanto a indústria doméstica rural pertencem a esse espaço da moradia (Tilly; Scott, 1987). As atividades acontecem num mesmo local, sejam elas preferencialmente orientadas para a troca ou para a subsistência. Segundo a descrição do cotidiano de uma unidade doméstica urbana por Mumford, 
os membros comiam juntos à mesma mesa, trabalhavam nas mesmas salas, dormiam no mesmo salão comum, convertido à noite em dormitório, juntavam-se às orações de família, participavam das diversões comuns (Mumford, 1998:307).

Essa não funcionalidade ${ }^{1}$ dos espaços está menos relacionada à ausência de hábitos de higiene ou de organização, como Mumford tende a interpretar, e mais à pouca hierarquia entre os membros do grupo. A elevação da moradia a templo da família patriarcal inicia-se apenas no século XVII, com o surgimento do capitalismo comercial na Holanda, justamente num contexto em que a burguesia torna-se classe dominante. Apenas a partir disso, valores do mundo doméstico burguês - como a intimidade - determinam uma progressiva especialização dos espaços domésticos (Mota, 2010).

As indústrias domésticas rurais $e$ as oficinas dos artesãos urbanos, com sua relativa autonomia, são aos poucos transformadas em empresas familiares pelo sistema putting-out, que preponderou sobretudo entre os séculos XVI e XVIII (Marx, 2010; Decca, 1982; Marglin, 1996). Sua base está no controle da distribuição de matéria-prima, ferramentas e produtos pelo capitalista mercador, enquanto a produção propriamente dita continua sendo realizada no espaço doméstico. A figura do mercador é o pivô do processo, responsável por distribuir a matéria-prima aos produtores de quem depois compra os produtos acabados, quase sempre com direitos exclusivos.

Essa divisão do trabalho é a primeira forma capitalista de produção pois, até então, o mercador atuava somente na esfera

1 O espaço doméstico tradicional não é multifuncional; ele simplesmente não é funcionalizado. Devo à minha orientadora de doutorado o emprego adequado do termo para designar espaços que não são especializados em determinadas atividades. Segundo Kapp (2013), "seria um anacronismo descrever as unidades domésticas mais antigas a partir da referência de multifuncionalidade. O próprio termo multifuncionalidade é inadequado se associarmos a ele o rearranjo de um mesmo local para diferentes eventos ou situações, como seria o caso de um moderno espaço de trabalho "multifuncional". 
da circulação. A esfera da produção não era capitalista, porque os artesãos podiam até produzir para o capital, mas não pelo capital. O capital mercantil estabelecia "propositadamente uma relação indireta e oblíqua com a "produção'" (Mariutti, 2012:1). O simples capital circulante era suficiente para reproduzir-se e não havia interesse do mercador de investir em capital fixo. Além disso, os estados nacionais europeus em formação amparavam os mercadores, articuladores dos diversos circuitos econômicos, em troca da consolidação do seu poder no território (Mariutti, 2012). O lucro estava fundamentado na especulação, na compra $e$ venda de mercadorias por preços não correspondentes ao seu valor (ou seja, ao tempo de trabalho socialmente necessário para produzilas).

Nessas circunstâncias, prevalecia nas unidades domésticas rurais e urbanas a organização denominada por Marx (2010) de "cooperação simples". Ou seja, o trabalho combinado em jornadas coletivas produz maior quantidade de valores de uso, comparado à soma de jornadas individuais, ao reduzir o tempo necessário para a obtenção de determinado efeito útil (Marx, 2010). A produtividade na cooperação simples está relacionada com essa redução do tempo, ao mobilizar uma força produtiva de trabalho social. Nesse mesmo texto, o autor exemplificou cada um desses efeitos úteis do trabalho combinado em várias atividades produtivas, como a construção, a pesca e a lavoura, conforme Quadro 1.

Mas é fácil perceber que esses efeitos úteis do trabalho combinado aplicam-se a inúmeras situações dentro e fora do universo da produção. Ou seja, eles não são exclusivos de espaços de trabalho produtivo e aplicam-se também ao universo da reprodução. As diversas atividades desempenhadas pelos membros das antigas unidades domésticas eram organizadas considerando-se os efeitos úteis do trabalho coletivo.

A partir do momento que o mercador decide organizar a produção orientada para a geração de mais-valia, ou para a extração de trabalho não pago, surge a divisão vertical ou a separação entre o trabalho manual dos artesãos e o trabalho 
intelectual desse novo capitalista, o putter-out. Seu lucro não advém mais da reprodução do capital circulante ou dos favores do Estado, e sim da organização hierárquica da produção, favorecendo a subsunção formal do trabalho ao capital. O trabalhador perde o controle sobre o produto e sobre o processo de trabalho. $\mathrm{O}$ fornecimento de matéria-prima e a encomenda de determinado produto incorporam ao capital do mercador o uso da força de trabalho pelo tempo necessário para a produção da quantidade solicitada de mercadoria. O camponês ou o artesão, que antes trabalhava para o sustento do seu grupo, passa a organizar seu tempo e seu espaço segundo as determinações da encomenda. $\mathrm{O}$ ritmo de trabalho permanece autorregulado, com interrupções diárias, meios-expedientes e feriados (Braverman, 1981), mas estendem-se as horas de dedicação para a produção de excedente.

\section{Quadro 1 - Efeitos úteis do trabalho combinado e respectivos exemplos de Marx (2010)}

\begin{tabular}{|l|l|}
\hline \multicolumn{2}{|c|}{ Trabalho Coletivo } \\
\hline $\begin{array}{l}\text { Efeito útil do trabalho } \\
\text { combinado }\end{array}$ & Exemplos \\
\hline $\begin{array}{l}\text { Elevação da potência } \\
\text { mecânica do trabalho }\end{array}$ & $\begin{array}{l}\text { "[...] levantar uma carga, fazer girar uma pesada } \\
\text { manivela ou remover um obstáculo" (p. 379) }\end{array}$ \\
\hline $\begin{array}{l}\text { Ampliação do espaço em } \\
\text { que atua o trabalho }\end{array}$ & $\begin{array}{l}\text { "[...] construção de diques, com obras de } \\
\text { irrigação, canais estradas, ferrovias etc." (p. 382) }\end{array}$ \\
\hline $\begin{array}{l}\text { Redução do espaço em } \\
\text { relação à escala de } \\
\text { produção }\end{array}$ & $\begin{array}{l}\text { "Mas custa menos trabalho construir uma oficina } \\
\text { para 20 pessoas do que 10 oficinas, cada uma } \\
\text { com capacidade para duas pessoas [...]" (p. 377) }\end{array}$ \\
\hline $\begin{array}{l}\text { Mobilização de muito } \\
\text { trabalho em momento crítico }\end{array}$ & $\begin{array}{l}\text { "[...] tosquiar um rebanho de ovelhas ou de } \\
\text { ceifar e colher um campo de trigo, a quantidade } \\
\text { e a qualidade do produto dependem de se } \\
\text { iniciarem e se concluírem em tempos fixados } \\
\text { essas operações" (p. 381) }\end{array}$ \\
\hline $\begin{array}{l}\text { Emulação entre indivíduos, } \\
\text { animando-os e estimulando- } \\
\text { os na execução de tarefas } \\
\text { repetitivas }\end{array}$ & $\begin{array}{l}\text { "Pedreiros, por exemplo, que fazem passar tijolos } \\
\text { de mão em mão até o alto de um andaime, } \\
\text { executam todos eles a mesma tarefa [...] todos } \\
\text { em conjunto, fazendo, o chegar ao ponto de } \\
\text { destino mais rapidamente do que o fariam se } \\
\text { cada um deles carregasse separadamente seu }\end{array}$ \\
\hline
\end{tabular}




\begin{tabular}{|l|l|}
\hline & $\begin{array}{l}\text { tijolo até o alto do andaime" (nota de rodapé, p. } \\
\text { 380) }\end{array}$ \\
\hline $\begin{array}{l}\text { Realização de diversas } \\
\text { operaçes ao mesmo tempo } \\
\text { em um processo de trabalho } \\
\text { complicado }\end{array}$ & $\begin{array}{l}\text { "Um rema, outro governa o leme, outro lança a } \\
\text { rede orpoa o peixe, e a pesca alcança um } \\
\text { resultado impossivel de obter sem essa } \\
\text { cooperação" (nota de rodapé, p. 381) }\end{array}$ \\
\hline $\begin{array}{l}\text { Poupança dos meios de } \\
\text { produção em virtude de seu } \\
\text { uso comum }\end{array}$ & $\begin{array}{l}\text { "Construções onde muitos trabalham, depósitos } \\
\text { para matéria-prima etc., recipientes, } \\
\text { instrumentos, aparelhos etc. que servem a muitos } \\
\text { simultânea ou alternadamente, em suma, uma } \\
\text { parte dos meios de produção é agora utilizada } \\
\text { em comum no processo de trabalho" (p. 377) }\end{array}$ \\
\hline $\begin{array}{l}\text { Empréstimo ao trabalho } \\
\text { individual do caráter do } \\
\text { trabalho social médio }\end{array}$ & $\begin{array}{l}\text { "Em cada ramo de atividades, o trabalhador } \\
\text { individual, Pedro ou Paulo, difere mais ou menos } \\
\text { do trabalhador médio. Essas diferenças } \\
\text { individuais, chamadas em matemática de erros, } \\
\text { compensam-se e desaparecem quando se toma } \\
\text { certo números de trabalhadores" (p. 376) }\end{array}$ \\
\hline
\end{tabular}

Fonte: Marx (2010). Elaboração da autora.

Apesar de as técnicas continuarem as mesmas, a divisão do trabalho assume novas funções e novas hierarquias no interior desse primeiro processo capitalista de produção, pois "a organização hierárquica do trabalho não tem como função social a eficácia técnica, mas a acumulação" (Marglin, 1996:41).

É mesmo peculiar ao modo de produção capitalista separar os diferentes trabalhos, em consequência também $\mathrm{o}$ trabalho mental e o manual - ou os trabalhos em que predomina um qualificativo ou o outro - e reparti-los por diferentes pessoas, o que não impede que o produto material seja o produto comum dessas pessoas ou que esse produto comum se objetive em riqueza material; tampouco inibe ou de algum modo altera a relação de cada uma dessas pessoas com o capital: a de trabalhador assalariado $e$, no sentido eminente, a de trabalhador produtivo. Todas essas pessoas estão não só diretamente ocupadas na produção de riqueza material, mas também trocam seu trabalho diretamente por dinheiro como capital e, por isso, reproduzem de imediato, além do próprio salário, mais- 
valia para o capitalista. $\mathrm{O}$ trabalho delas consiste em trabalho pago + trabalho excedente não pago (Marx, 1987:403).

Surge, assim, a supracitada divisão vertical entre trabalho intelectual e manual, bem como uma divisão horizontal, que consiste no desmembramento do processo de produção em operações distintas, possível apenas porque a organização desse processo já é realizada verticalmente (Marx, 2010; Braverman, 1981). Essa divisão horizontal difere da divisão do trabalho na sociedade em geral, porque ela não é fundada na diferença entre produtos e matérias-primas empregadas, mas na segmentação das tarefas realizadas pelos trabalhadores na feitura de um único produto (Braverman, 1981). Finalmente, há uma nova divisão do trabalho por sexo, a qual as análises centradas na esfera da produção raramente reconhecem, mas que destrói o compartilhamento de atividades por todos os membros da família.

O surgimento do sistema putting-out foi uma maneira de o capital contornar as regras das corporações de ofício a que esses artesãos estavam submetidos e que interditavam tanto a simples disponibilização da força de trabalho no mercado, quanto "a transformação de um mestre artesão em capitalista" (Marx, 2010:413). A limitação do número de aprendizes que cada mestre podia empregar, a venda de produtos e não do trabalho como mercadoria e a propriedade dos meios de produção contribuíram para a defesa das corporações contra o capital; "faltava a base principal da manufatura, a separação do trabalhador de seus meios de produção e a conversão desses meios em capital" (Marx, 2010:414). As corporações operavam com uma certa divisão do trabalho e uma certa hierarquia, mas ambas de natureza bem diferente da organização capitalista da produção. Sua divisão era essencialmente técnica, consistindo numa separação das etapas da produção que economizasse tempo e esforço, mas sem o parcelamento em tarefas destituídas de sentido (Braverman, 1981); Marglin, 1996). E sua hierarquia era especialmente linear, entre mestres (que já haviam sido aprendizes) e aprendizes (que se 
tornariam mestres), fazendo do espaço de trabalho também um lugar de formação ou qualificação para um ofício especializado.

A descrição mais corrente da organização dessas corporações - tal como delineada no parágrafo anterior - refere-se a associações tradicionais de artesãos nas áreas urbanas na Inglaterra Medieval, e que ainda mantinham indivisas as atividades produtivas e reprodutivas. Essa descrição é comum a autores que estudam o trabalho a partir da esfera da produção $e$ não se propõem a problematizar a sua relação com a esfera da reprodução. Eles tendem a generalizar a existência das corporações de ofício, orientadas para o comércio local, por toda a Europa, e tomá-las como exemplo de espaços não opressores, o que não é correto (Olgivie, 2002). Ao contrário da experiência da Inglaterra e também da Holanda, na maior parte da Europa, como Alemanha, Suíça, Áustria, Bohemia, Itália, Espanha, Grécia, Bulgária e Sérvia, as corporações de ofício localizavam-se em áreas rurais, eram orientadas para o mercado externo, trabalhavam para atender as demandas dos mercadores $e$ sobreviveram até a Idade Moderna (Olgivie, 2002). A relação entre os universos de produção e de reprodução nas corporações de ofício permanece polêmica entre os historiadores que investigam as questões de trabalho e de gênero.

Os estudos de Jane Gray (1993) sobre a indústria irlandesa do linho em meados do século XVIII, por exemplo, indicam que houve ali um crescimento baseado na desigualdade entre unidades domésticas rurais de fiação e unidades domésticas rurais de tecelagem, localizadas, respectivamente, nas regióes oeste $e$ leste da província de Ulster. A fiação, realizada por mulheres $e$ crianças nos interstícios do trabalho diário e muito mal remunerada, concentrava-se em distritos onde ainda havia terras comuns para a agricultura de subsistência (Gray, 1993). A tecelagem, realizada por homens em ritmo industrial e por uma remuneração mais alta, localizava-se em distrito onde as antigas terras comuns já haviam sido cercadas. Essa diferença sócioespacial tornou possível a discrepância nos preços pagos ao trabalho (feminino) de fiação $e$ ao trabalho (masculino) de 
tecelagem. Isto é, a mobilização de um exército de mulheres $e$ crianças para fornecer fio barato à indústria do linho deu-se pelo fato de essas mulheres e crianças garantirem a reprodução da família com a agricultura de subsistência, realizada paralelamente à fiação. Já os trabalhadores da tecelagem dependiam do salário para sobreviver, embora também contassem com as atividades domésticas realizadas invariavelmente por uma mulher:

tanto nos domicílios onde o trabalho masculino era a principal fonte de renda em dinheiro, quanto em domicílios onde o trabalho feminino era o maior elo com a economia monetária, produtores industriais rurais associavam o trabalho feminino com o "trabalho doméstico" (Gray, 1998:18). ${ }^{2}$

Em suma, o espaço da moradia no sistema putting-out continuou abrigando atividades de produção e de reprodução, mas submeteu-as a uma nova hierarquia patriarcal.

As chamadas guildas ou associações entre pessoas com interesse comum, de fundo religioso, cultural, social ou político, existiram por toda a Europa, desde a Antiguidade. As corporações de ofício representavam um tipo especial de guilda, de produção artesanal que agregava profissionais independentes num determinado ramo de produção, cujos propósitos eram eminentemente econômicos: obter a exclusividade no direito de praticar uma específica atividade econômica em determinada região, em razão de privilégios concedidos pelas autoridades políticas da cidade onde a guilda estava localizada. Ao lado das guildas de merchants, as de artesãos eram as mais comuns na Europa durante a Idade Média até a Idade Moderna.

2 "[...] that both in households where men's work was the primary source of cash income, and in households where women's work was the main link to the money economy, rural industrial producers associated women's work with 'housework" (Gray, 1998:18). Todas as traduções foram feitas pela autora do artigo. 
"Guildas artesanais" eram associações de mestres artesãos em um determinado ramo de fabricação; "Guildas mercantis" eram associações de comerciantes em uma determinada localidade ou de uma determinada linha de produtos. Guildas mercantis surgiram antes das corporações de ofício, mas ambas eram generalizadas na Europa por volta do século XII. Guildas de ambos os tipos começaram a perder seus poderes em algumas partes da Holanda e da Inglaterra no século XVI, mas sobreviveram na França e em muitas partes da Alemanha, Itália, Escandinávia e Ibéria até o final do século XVIII. Alguns territórios alemães não aboliram as corporações até o fim do século XIX; Württemberg, por exemplo, manteve as suas alianças até 1864 (Olgivie, 2002:1). ${ }^{3}$

Os estudos histórico-sociais de Crowston (2006) sobre a questão do gênero indicam a prevalência de um padrão patriarcal nas guildas de artesãos, embora haja uma divergência na indicação da data de origem dessas associações, pois enquanto Olgivie (2002) indica o século XII, Crowston (2006) assinala os séculos XV e XVI. Os membros eram em sua maioria do sexo masculino, os estatutos proibiam a entrada de aprendizes do sexo feminino $e$ as mulheres relacionadas aos membros das corporações - mães, filhas, esposas etc- se ocupavam exclusivamente do trabalho doméstico (Crowston, 2006; Olgivie, 2007).

Olgivie (2007) concebe as guildas de artesãos como monopólios. Nessa perspectiva, as restrições legais à participação de mulheres, além das já citadas hierarquia linear e restrição no

3 "Craft guilds" were associations of master artisans in a particular branch of manufacturing; "merchant guilds" were associations of traders in a particular locality or a particular line of wares. Merchant guilds arose before craft guilds, but both were widespread in Europe by the twelfth century. Guilds of both sorts began to lose their powers in some parts of the Netherlands and England in the sixteenth century, but they survived in France and most parts of Germany, Italy, Scandinavia, and Iberia into the late eighteenth century. Some German territories did not abolish guilds until the later nineteenth century; Württemberg, for instance, retained its guilds until 1864. 
número de aprendizes, eram recursos empregados por essas associações para manter os privilégios no mercado externo. Uma outra estratégia foi adotada por guildas de alfaiates na França no século XVIII: para garantir a mobilidade social ascendente de seus filhos (homens), os mestres artesãos casavam-nos com filhas de mestres artesãos de guildas de maior prestígio; já as filhas, casavam-nas com jornaleiros, aspirantes a aprendizes da própria guilda, condenando as mulheres a permanecerem em uma economia familiar patriarcal (Crowston, 2006).

Crowston, ao investigar o papel da mulher fora das corporações, evidencia a sua participação marginal no mercado de trabalho, na formação profissional, nos privilégios das guildas: "Meninas, mulheres e suas famílias aproveitaram brechas, interstícios e autorização tácita ou manifesta para obter formação, emprego, parceria e até mesmo adesão da guilda autônoma" (Crowston, 2006:28). Porém, ao argumentar que as mulheres desenvolveram estratégias para resistir ao corporativismo das guildas de artesãos, Crowston acaba por demonstrar a estreita relação entre a economia "forte" dessas instituições e a economia "fraca" das mulheres. O valor moral que determina uma economia "forte" e "fraca" relaciona-se à adesão ou não do trabalhador às corporações de ofício. Quem trabalha "fora" das corporações é considerado um trabalhador ilícito, cujo trabalho não é digno (Crowston, 2006). A concentração de trabalhadores no espaço subsiste a partir da dispersão de maior número de trabalhadoras, e bem antes da origem do sistema de fábrica. Dois exemplos são clássicos: a já mencionada relação entre mulheres fiadoras e homens tecelões, cujas corporações coagiam as mulheres a trabalhar abaixo do valor de mercado (Olgivie, 2007); $e$ a relação entre guildas de alfaiates e guildas de costureiras na França do século XVII, que mantinha uma segregação sexual do trabalho (Crowston, 2006).

Neste último caso, mesmo estando as mulheres organizadas em guildas, a exploração do trabalho por gênero evidencia-se pelo controle do mercado por parte das guildas de alfaiates. Guildas de costureiras obtiveram autorização para funcionar em razão da 
baixa capacidade de produção das guildas de alfaiates $e$ da grande quantidade de mulheres pobres, trabalhando ilicitamente. $\mathrm{O}$ controle era realizado mediante vários recursos, dependendo da capacidade de organização dos homens e das mulheres. Em Paris, guildas de costureiras tinham a permissão de fabricar somente roupas para mulheres e crianças, enquanto guildas de alfaiates permaneciam com o direito de produzir roupas para mulheres $e$ homens, além das roupas usadas pelas mulheres da corte. Em Rouen, guildas de costureiras pagavam compulsoriamente taxas para as de alfaiates, mas sem participar da administração (Crowston, 2006).

Para Crowston (2006), a capacidade de resistência das mulheres organizadas está relacionada com a capacidade de controle dos mestres artesãos. Essa relação fica evidente nos estudos realizados por ela na França, que sugerem variações regionais da capacidade de organização coletiva.

Esse contraste norte-sul espelha uma distinção notável na mais ampla historiografia, que descreve uma forte tradição corporativa no norte versus uma fraqueza nas guildas no sul. Essa coincidência sugere que, quando a tradição corporativa era forte, as costureiras poderiam atingir estatuto formal de mestres, com privilégios e restrições inerentes a elas. Onde as corporações eram mais fracas, $e$ as mulheres não tinham papel corporativo prévio, elas permaneceram auxiliares $e$ em grande parte membros mudas de guildas de alfaiates. Foi a vitalidade da tradição das guildas dentro das cidades do norte que aparelhou mulheres com os instrumentos conceituais e legais para argumentar a favor de seus direitos corporativos autônomos (Crowston, 2006:21). ${ }^{4}$

4 "This north-south contrast mirrors a distinction noted in the wider historiography, which describes a strong corporate tradition in the north versus the weakness of guilds in the south. This coincidence suggests that where the corporate tradition was strong, seamstresses could attain formal mistress status, with the privileges and constraints inherent in it. Where guilds were weaker, and women had no previous corporate role, they remained auxiliary and largely voiceless members of tailors' guild. It was the vitality of the guild tradition within 
Ou seja, a capacidade de resistência das guildas femininas prevê o emprego dos mesmos recursos utilizados pelas guildas masculinas, o que não configura a capacidade autônoma de elaboração das próprias normas, mas uma reprodução das normas vigentes. Para além de um discurso feminista, embora algumas guildas de mulheres tenham obtido emancipação em certas regióes da França, como nas de Aix e Provença (Crowston, 2006), não se pode generalizar dizendo que esses espaços eram livres de opressão. Mesmo porque, embora essas poucas guildas femininas demonstrassem capacidade de adotar normas de guildas masculinas, na grande maioria dos casos o direito foi concedido pelo rei ou mestre artesão, em uma relação de inclusão subordinada.

Portanto, ao contrário de algumas análises marxistas, as corporações de ofício não devem ser consideradas como espaços de trabalho livres de relações opressoras, considerando-se a divisão do trabalho por gênero fora e dentro das corporações. A mão de obra feminina, ao lado de outros proletários em situação de miséria, já existe como acessória aos trabalhadores membros das guildas de artesãos desde as origens das corporações de ofício, antecipando a superexploração do que se denomina, na economia contemporânea, de trabalho formal $e$ informal.

\section{Do espaço doméstico à fábrica}

A passagem do sistema putting-out para o sistema fabril (manufatura e maquinaria) indica a implantação, pelo capitalista, de formas distintas de organização racional do trabalho coletivo. Longe de ser uma questão de gradação tecnológica (Braverman, 1981; Marglin, 1996), essa transformação fundamenta-se na implantação de novos instrumentos gerenciais, específicos de extração de mais-valia relativa. Essa passagem revela como o espaço transforma-se em condição para que o capital domine,

northern cities that furnished women with the conceptual and legal tools to argue for their autonomous corporate rights" (Crowston, 2006:21). 
além da forma, a matéria do trabalho, a partir da modificação do sistema putting-out nos espaços domésticos para o sistema de fábrica nos locais exclusivos de produção. No sistema de fábrica, novos papéis são atribuídos às mulheres, dentro $e$ fora das fábricas. Portanto, esta seção aborda as alterações no processo de trabalho e, em um segundo momento, as novas formas de opressão de gênero no sistema fabril.

Tão logo o contrato de trabalho assalariado disseminou-se pela Europa, o mercador apropriou-se da força coletiva existente nas antigas unidades domésticas. O trabalho combinado de trabalhadores submetidos simultaneamente a um plano de produção em grande escala é a primeira forma de cooperativa em bases capitalistas. Na área urbana, o capitalista expande o número de trabalhadores da oficina do mestre artesão, não alterando as bases técnicas de produção (Marx, 2010). Na área rural, o capitalista coordena o trabalho combinado de várias unidades domésticas, agora atuando em atividades produtivas parciais:

A atuação simultânea de grande número de trabalhadores, no mesmo local, ou, se se quiser, no mesmo campo de atividade, para produzir a mesma espécie de mercadoria sob o comando do mesmo capitalista constitui, histórica $e$ logicamente, o ponto de partida da produção capitalista (Marx, 2010:375).

Os efeitos úteis do trabalho coletivo aplicam-se a outras formações sociais, além das sociedades capitalistas, como às "comunidades primitivas" e às sociedades da antiguidade (Marx, 2010). Além disso, predomina o emprego dos efeitos úteis do trabalho coletivo em qualquer formação social contemporânea em que esse trabalho é pouco hierarquizado e subdividido. ${ }^{5}$ Mas a cooperação em bases capitalistas difere das formas anteriores de cooperação simples porque pressupõe a figura da gerência, que aglomera os trabalhadores, supervisiona os processos conjuntos

5 Devo à minha orientadora essa contribuição. 
de trabalho e concentra os meios de produção. Em outras palavras, a cooperação sob o modo capitalista de produção contempla, além da extração de mais-valia absoluta (prolongamento da jornada de trabalho), a mais-valia relativa (aumento da capacidade produtiva do trabalho) que já surge pelo simples fato de o capital se apropriar, gratuitamente, da força produtiva do trabalho social (Marx, 2010), antes mesmo de qualquer medida de racionalização do processo produtivo.

A combinação dos trabalhadores na cooperação simples não pressupõe a existência de um espaço delimitado, particularizado, como aquele da fábrica da manufatura, mesmo quando o trabalho combinado está submetido às ordens do capital. A centralização dos trabalhadores coletivos em um mesmo local origina-se da necessidade de criar um dispositivo disciplinar para combater as "fraudes" causadas por aqueles subcontratados (Marglin, 1996). O sistema putting-out mostrou-se ineficaz, do ponto de vista do capitalista, diante das inúmeras "sabotagens" empreendidas pelos produtores: o desvio de parte da produção, a falsificação dos produtos, a utilização de matérias-primas de qualidade inferior àquelas fornecidas pelo capitalista etc (Decca, 1982).

Ao centralizar o trabalho cooperativo, os espaços exclusivos de produção permitem a implantação de outros mecanismos de controle pela gerência, além do prolongamento da jornada e da apropriação gratuita da força produtiva do trabalho social. Esses novos mecanismos de controle vão desde a especialização das tarefas na manufatura até o desenvolvimento de máquinasferramenta na maquinaria. $\mathrm{O}$ aumento de produtividade ou a redução do tempo de trabalho socialmente necessário para a produção de determinada mercadoria é obtido pela expropriação do saber do artesão, que reduz o trabalho vivo à tarefa simples, prescrita pela organização racional do trabalho. A implantação desses mecanismos nos espaços exclusivos de produção determinou a distribuição espacial dos trabalhadores coletivos coordenados no tempo e no espaço pela gerência. 
Marx (2010) indica a existência de perversas relações de opressão entre o sistema fabril e o sistema putting-out.

Em contraste com o período manufatureiro, o plano da divisão do trabalho baseia-se no emprego de mulheres, de crianças de todas as idades, de trabalhadores sem habilitação, sempre que possível; enfim, na mão de obra barata, no "cheap labour", como a chamam os ingleses. Isto se aplica não só à produção organizada em grande escala, com ou sem emprego de maquinaria, mas também à indústria a domicílio, exercida nas residências dos trabalhadores ou em pequenas oficinas. Essa indústria a domicílio moderna só tem o nome em comum com a antiga, que pressupunha $\mathrm{o}$ artesanato urbano independente, a economia camponesa independente $e$ a casa da família do trabalhador. A indústria a domicílio se converteu hoje na seção externa da fábrica, da manufatura ou do estabelecimento comercial. Além dos trabalhadores fabris, de manufatura e dos artesãos, que se concentra em grande número num mesmo local e comanda diretamente, o capital põe em movimento, por meio de fios invisíveis, um grande exército de trabalhadores a domicílio, espalhados nas grandes cidades e pelo interior do país. É o caso da camisaria dos Tillie, em Londonderry, Irlanda, que, na fábrica propriamente, emprega 1.000 trabalhadores $e$, espalhados pelo campo, 9.000 trabalhadores a domicílio (Marx, 2010:524).

A exploração abusiva na manufatura e nos espaços de domicílio modernos é vastamente ilustrada por Marx (2010). Nas manufaturas metalúrgicas, mulheres e crianças são empregadas em atividades da cadeia produtiva em que as condições de trabalho são insalubres. Na fabricação de livros, as atividades de impressão e encadernação proporcionam a exploração de jovens $e$ homens por meio de horas em excesso de trabalho. Nas olarias, todo o processo de produção é executado por crianças e mulheres que se submetem a trabalho em excesso e pesado. No trabalho das indústrias em domicílio, notadamente no ramo de produção 
de rendas, a divisão de trabalho por gênero fica mais evidente. As péssimas condições e o trabalho em excesso e mal pago predominam nas etapas da cadeia produtiva trabalho-intensivas, como o acabamento $e$ as rendas feitas com bilros (Marx, 2010). As atividades de acabamento são realizadas por crianças e mulheres em suas residências ou nas denominadas "casas de patroas", nas áreas urbanas. As atividades de artesanato feitas com bilros são executadas por crianças $e$ jovens do sexo feminino em suas pequenas residências ou em "escolas de renda" mantidas por mulheres pobres em seus casebres, nas áreas rurais.

Como mencionado antes neste texto, o emprego de mão de obra externa, contratada para a realização de tarefas parciais na indústria de lá, é pioneiro quando as indústrias domésticas subordinavam-se às determinações de poderosas corporações de ofício, ainda no século XVII. Após a Revolução Industrial, a divisão parcelada do trabalho expande-se para a sociedade como um todo, inaugurando a generalização de unidades fabris parciais, hoje denominadas "empresas terceirizadas". Ou seja, a unidade doméstica presta determinado serviço à unidade fabril, considerando que a primeira executa uma atividade material parcial referente a uma etapa da cadeia produtiva de menor valor agregado, enquanto a segunda realiza o trabalho de montagem do produto final e sua comercialização.

À medida que o sistema de produção fabril se desenvolve, outra atividade parcial, porém menos evidente, é desempenhada pela mulher na sociedade capitalista: a de transformar a mercadoria comprada pelo trabalhador assalariado em mercadoria em condições de uso. Illich denomina esse trabalho de shadow work, porque não se paga e nem sequer se percebe "o tempo, a labuta e o esforço que deve ser despendido no sentido de adicionar valor a qualquer mercadoria comprada, sem o que não seria possível usá-la" (Illich, 1982:47) ${ }^{6}$. Ele demonstra em que consiste o shadow work, comparando os procedimentos de uma

6 "The time, toil and effort which must be expended in order to add to any purchased commodity value without which it is unfit for use" (Illich, 1982:47). 
moderna dona de casa e de uma mulher campesina para executar uma tarefa corriqueira: fritar um ovo.

Quando uma dona de casa moderna vai ao mercado, pega os ovos, leva-os para sua casa em seu carro, pega o elevador até o sétimo andar, liga o fogão, pega a manteiga do refrigerador, e frita os ovos, ela adiciona valor a uma mercadoria em cada um desses passos. Isso não é o que sua avó realizava. Ela procurava ovos no galinheiro, cortava um pedaço de banha de porco que ela havia processado, acendia alguma lenha que suas crianças tinham coletado nas terras comuns e adicionava sal que ela havia comprado. Embora esse exemplo deve parecer romântico, ele torna a diferença mais clara. Ambas as mulheres preparam ovos fritos, mas somente uma usa uma mercadoria do mercado $e$ bens de produtos altamente capitalizados: carro, elevador, eletrodomésticos. A avó realiza tarefas específicas de gênero feminino na criação de subsistência; a jovem dona de casa deve tolerar a carga doméstica do shadow work (Illich, 1982:48). ${ }^{7}$

A dona de casa moderna contribui com a acumulação ampliada do capital de duas maneiras: primeiro, realizando a produção na esfera da circulação ao empregar produtos capitalizados, tal como ocorre com o trabalhador assalariado que adquire a mercadoria com o seu salário; além disso, ela também

7 "When a modern housewife goes to the market, picks up the eggs, drives them home in her car, takes the elevator to the seventh floor, turns on the stove, takes butter from the refrigerator, and fries the eggs, she adds value to the commodity with each one of these steps. This is not what her grandmother did. The latter looked for eggs in the chicken coop, cut a piece from the lard she had rendered, lit some wood her kids had gathered on the commons, and added the salt she had bought. Although this example might sound romantic, it should make the economic difference clear. Both women prepare fried eggs, but only one uses a marketed commodity and highly capitalized production goods: car, elevator, electric appliances. The grandmother carries out woman's gender specific tasks is creating subsistence; the new housewife must put up with the household burden of shadow work' (Illich, 1982:48). 
agrega valor ao terminar de transformar a mercadoria em produto consumivel.

A domesticação da mulher a partir de uma organização espacial patriarcal fica mais evidente na moderna residência burguesa. Além da já citada especialização dos espaços, essa residência caracteriza-se pela exaltação da privacidade em ambientes íntimos, aconchegantes e seguros, que contrastam com os espaços externos, de domínio dos homens, e considerados perigosos (de Mare, 1999).

A organização espacial patriarcal separa os espaços de produção e reprodução, $e$ as modernas fábricas representam o grau máximo dessa separação. À medida que a divisão espacial entre produção e reprodução se radicaliza, novos mecanismos de controle social são elaborados dentro e fora das fábricas.

\section{Da fábrica ao espaço doméstico}

O trabalhador individual na manufatura, com sua ferramenta especializada, encarcerado e fixado em seu posto de trabalho, possibilitou a sistematização das práticas de gerência que, por sua vez, deram início ao desenvolvimento da organização racional do trabalho, a partir dessa função exclusiva. As três correntes principais, que perduram até hoje no chão de fábrica, são denominadas taylorismo, fordismo e toyotismo. Esta seção discorre sobre a relação entre os preceitos de cada uma dessas correntes $e$ a função dos supervisores do trabalho vivo ou dos trabalhadores técnico-científicos. A gerência da organização racional aplica-se ao trabalho concentrado na fábrica, notadamente realizado pelo homem médio. Naquele disperso em unidades residenciais permanece a gerência primitiva, em referência ao capitalista putter-out, em que há a prevalência de mulheres que realizam o trabalho de produção e de reprodução.

A organização do trabalho nas oficinas manufatureiras e nas fábricas foi sistematizada por Frederick Winslow Taylor, que, em 1911, inaugurou uma nova teoria e uma nova prática com a publicação de seus Princípios de Gerenciamento Científico (The 
Principles of scientific Management). Essa obra tinha a pretensão de aplicar os princípios da ciência aos problemas complexos $e$ crescentes do controle do trabalho operário (Braverman, 1981). Porém, há de se lembrar que a pretensa cientificidade do método taylorista residia no seu objeto de investigação: a adaptação do trabalho às necessidades do capital, $e$ não $o$ trabalho propriamente dito (Braverman, 1981). O objetivo de Taylor era estudar os fatores que proporcionavam o rendimento máximo do trabalhador individual em um dia: a especificação da tarefa a ser executada, o tempo exato permitido, a força máxima, o movimento mínimo etc. A concepção do homem como máquina (Moraes Neto, 1986), característica do taylorismo, somente é possível a partir do homem-padrão: trabalhador do sexo masculino e jovem. Embora seus princípios fossem divulgados no auge da Revolução Industrial, a base técnica do trabalho investigado por Taylor continuava manufatureira, ou seja, fundamentada na habilidade do trabalhador.

A divisão técnica e a organização racional do trabalho, aliadas ao desenvolvimento de novas técnicas de produção (manufatura e maquinaria), são apontadas por teóricos marxistas (Marglin, 1996; Gorz, 1996; Pignon; Querzola, 1989) como a base material de reprodução das relações capitalistas de produção dentro dos espaços fabris. A distinção entre operários trabalhadores e supervisores expressa uma disciplina militar (Marx, 2010), a qual origina um conhecimento especializado, separado do processo manual.

O planejamento do trabalho com o objetivo de maximizar a produtividade física do trabalhador também está presente no fordismo. Na década de 1920, Henri Ford levou o taylorismo ao extremo ao introduzir as esteiras rolantes em suas fábricas de automóveis, nos Estados Unidos. Esse novo mecanismo de transporte do produto ao longo das estações de trabalho tinha o objetivo de reduzir o tempo de deslocamento do objeto e eliminar o trabalho improdutivo de deslocamento do trabalhador dentro da fábrica. Apesar de sua alta produtividade, a linha de montagem não é uma inovação tecnológica, porque o processo de produção 
continua dependendo das habilidades do trabalhador manual: "o fordismo, a linha de montagem, é um desenvolvimento da manufatura, e não da maquinaria" (Moraes Neto, 1986:231).

O taylorismo e o fordismo, processos de administração dos tempos e movimentos do trabalho vivo (Moraes Neto, 1986), apesar da base técnica manufatureira, permaneceriam nos galpões da maquinaria, enquanto o mecanismo demandasse a habilidade do trabalhador e, evidentemente, seu trabalho material, mesmo que desqualificado. Esses sistemas fabris caracterizavam-se pela produção em grande escala de produtos padronizados, a denominada produção em massa.

Ford tinha o propósito de criar um novo tipo de sociedade baseada na regulação entre produção e consumo de massa, de modo que a produtividade fordista encontrasse uma demanda efetiva capaz de absorver o crescimento da produção. Para tanto, ele implantou em suas fábricas o dia de oito horas e cinco doláres. Além de disciplinar o trabalhador na operação da linha de montagem, o ganho no salário era suficiente para o trabalhador comprar e consumir a mercadoria em seu tempo livre (Harvey, 1998).

O fordismo atrelado ao americanismo, um grande esforço coletivo dos Estados Unidos para criar um novo tipo de trabalhador, cujo modo de vida estaria em comunhão com o espírito puritano sensível para a geração de lucro (Gramsci, 2001), demonstrou ser um ambicioso programa que garantiu a reprodução ampliada do capital e o deslocamento do eixo dinâmico da economia mundial da Europa para os Estados Unidos. Um novo tipo de sociedade surge a partir da fábrica, cuja vida está centrada no trabalho produtivo, ou mais especificamente, no mais-trabalho:

a vida na indústria exige um aprendizado geral, um processo de adaptação psicofísica a determinadas condições de trabalho, de nutrição, de habitação, de costumes etc., que não é algo inato, "natural", mas exige ser adquirido (Gramsci, 2001:251). 
Os efeitos desse modo de organização sobre o trabalhador $e$ a sociedade, em geral, são perversos. Além do trabalho alienado, desprovido de conteúdo, o compromisso fordista entre capital $e$ trabalho exclui mulheres, negros e outras maiorias sociais que não têm acesso ao emprego privilegiado, destinado a "uma força de trabalho predominante branca, masculina $e$ fortemente sindicalizada" (Harvey, 1998:132). Vários recursos de coerção social foram empregados para disciplinar os trabalhadores, dentro $e$ fora das fábricas, com o propósito de controlar a insatisfação, nas esferas de produção e reprodução.

Em 1916, Ford realiza uma curta experiência com assistentes sociais que visitavam os trabalhadores em suas residências, de modo a verificar a conduta moral e o consumo orientado, em uma nova tentativa de disciplinar o consumo de massa. O controle da "moralidade" dos operários é fundamental para garantir, fora da fábrica, a manutenção da eficiência muscular e nervosa do trabalhador, de modo a impedir seu colapso, coagido pelo novo método de produção (Gramsci, 2001). Ford interessa-se em regular tanto a organização das famílias, quanto as relações sexuais de seus empregados: "a verdade é que não se pode desenvolver o novo tipo de homem exigido pela racionalização da produção $e$ do trabalho enquanto o instituto sexual não for adequadamente regulamentado, não for também racionalizado" (Gramsci, 2001:252). Essa política de coerção tem claro objetivo de estender a disciplina operária para fora do recinto da fábrica.

Após 1945, surgem várias iniciativas para manter a subordinação dos trabalhadores. Cada vez mais a organização sindical dos trabalhadores (em sindicatos) é desmobilizada por ganhos de salário em troca do aumento de produtividade. No período pós-guerra, o Estado assume novos papéis de intervenção na economia (administração econômica keynesiana) e de controle social (estado do bem-estar social). Para evitar novas crises econômicas, como a de 1929, o Estado implanta políticas públicas dirigidas aos serviços e à infraestrutura urbana, garantindo o crescimento da produção, o consumo em massa e o emprego relativamente pleno. A fim de reduzir as tensões sociais, o Estado 
elabora políticas redistributivas $e$ ações legais que garantam seguridade social, assistência médica, habitação e serviços educacionais à maioria excluída (Harvey, 1998).

Diante da recessão de 1973 e da crise do petróleo, o regime de acumulação fordista não foi suficiente para manter os lucros das grandes corporações em patamares aceitáveis. Nas décadas de 1970 e 1980, elas adotaram um novo regime de acumulação capitalista, denominado acumulação flexível, associado a uma forma distinta de regulamentação política e social (Harvey, 1998). Perante o contexto de deflação e o aumento de competição, as empresas recorreram a novas formas de constituição "de acumulação flexível, do downsizing, das formas de gestão organizacional, do avanço tecnológico, dos modelos alternativos ao binômio taylorismo/fordismo" (Antunes, 2009:49). Em um momento de intensificação da concorrência intercapitalista, as organizações recorreram notadamente à experiência japonesa de reestruturação do processo produtivo, fundamentada no encurtamento do giro do capital e no corte de gastos com vigilância e controle da força de trabalho.

Esse encurtamento refere-se à redução do tempo de cada ciclo da produção, de modo a aumentar a lucratividade. A produção em pequenos lotes e os processos de inovação de produtos possibilitaram o atendimento a uma diversidade maior de nichos de mercado. Os processos produtivos adotaram um novo formato para reduzir o tempo de giro:

uso de novas tecnologias produtivas (automação, robôs) $e$ de novas formas organizacionais (como o sistema de gerenciamento de estoques "just-in-time", que corta dramaticamente a quantidade de material necessária para manter a produção fluindo) (Harvey, 1998:148).

$\mathrm{O}$ corte de gastos com vigilância e controle originou dois tipos de trabalho flexível. O primeiro, dentro das fábricas, eliminou os postos de trabalho improdutivos dos supervisores e retomou em parte o saber operário, ao restituí-lo de maior participação nos 
processos de decisão. "Equipes polivalentes", "células de produção", "times de trabalho" ou "grupos semiautônomos" designam a atuação em equipe, cujo objetivo é agilizar os processos produtivos ou reduzir o tempo de trabalho (Antunes, 2009). No entanto, o aparente controle operário sobre o processo de produção revela-se sob forma de opressão, por meio da determinação empresarial de engajamento ativo do trabalhador. "Reengenharia, lean production, team work, eliminação de postos de trabalho, aumento da produtividade, qualidade total, fazem parte do ideário (e da prática) cotidiana da "fábrica moderna" (Antunes, 2009:55). Nesse sentido, o que determina formatos horizontais de gestão na fábrica moderna é a necessidade de intensificar o trabalho vivo, a despeito da ideia que atribui à introdução da tecnologia computadorizada a demanda por um relacionamento mais cooperativo entre empregador e empregado (Tomaney apud Antunes, 2009). A nova gestão é por objetivos, de forma que a gerência possa controlar o trabalho por meio de indicadores de desempenho que avaliam se as metas determinadas a priori foram alcançadas ou não, e por meio de oferta de instrumentos técnicos e gerenciais para viabilizar o desempenho exigido (Salerno, 1999).

O segundo tipo de trabalho, fora das fábricas, reacendeu de maneira drástica a vulnerabilidade dos grupos desprivilegiados, pela precarização das condições trabalhistas. Harvey (1998) aponta uma nova forma de dualidade do mercado, entre trabalhadores do sexo masculino e brancos (incluídos) e negros, mulheres, minorias étnicas (excluídos). Segundo o autor, o advento do modo flexível de acumulação capitalista confere um papel de maior importância aos trabalhadores excluídos:

[...] a subcontratação organizada abre oportunidades para a formação de pequenos negócios e, em alguns casos, permite que sistemas mais antigos de trabalho doméstico, artesanal, familiar (patriarcal) e paternalista ("padrinhos", "patronos" e até estruturas semelhantes à da máfia) 
revivam e floresçam, mas agora como peças centrais, e não apêndices do sistema produtivo (Harvey, 1998:145).

A gestão por metas nas unidades parcializadas e dispersas difere da gestão centralizada nas unidades fabris e retoma o formato do sistema putting-out. Assim como na fábrica, a gerência determina os resultados quantitativos e qualitativos dos produtos encomendados, mas, à diferença do que ocorre no ambiente fabril, não atua no sentido de garantir as condições de produção. Tanto os instrumentos técnicos, quanto os organizacionais são de responsabilidade dos trabalhadores dispersos.

O novo convívio de unidades fabris com pequenas empresas ou unidades de trabalho doméstico, familiar $e$ paternalista, não é um simples retorno ao sistema putting-out. Ainda que estratégias combinadas de extração de mais-valia relativa e absoluta tenham existido desde a separação das esferas da produção e da reprodução ainda na Idade Média, a atual acumulação flexível difere de todas elas pela maior pressão da circulação e acumulação do capital financeiro, que culmina com a compressão do espaço e do tempo (Harvey, 1998). O giro acelerado do capital demanda maior agilidade na gestão e na organização do trabalho, determinando uma coordenação muito mais direta e estreita entre unidades capital-intensivas (as fábricas) $e$ unidades trabalho-intensivas (os pequenos negócios domésticos ou semidomésticos).

$\mathrm{Na}$ acumulação flexível, a empresa substitui a fábrica, no sentido de o espaço de produção desmembrar-se e dispersar-se de modo a alcançar a meta da venda. Tal como as unidades fabris dispersas tornam-se "empresas terceirizadas" da fábrica moderna, as unidades especializadas $e$ dispersas das empresas contemporâneas convertem-se em "prestadoras de serviços", pois a prerrogativa de fluxo acelerado de capital determina que o trabalho imaterial prevaleça sobre o trabalho material. Na lógica do capitalismo financeiro, a entrega de produtos parciais no prazo estabelecido e em conformidade com critérios de qualidade 
agregam mais valor ao produto que a produção propriamente dita.

Mas atualmente o capitalismo não é mais dirigido para a produção, relegada com frequência à periferia do Terceiro Mundo, mesmo sob as formas complexas do têxtil, da metalurgia ou do petróleo. É um capitalismo de sobreprodução. Não compra mais matéria-prima $e$ já não vende produtos acabados: compra produtos acabados, ou monta peças destacadas. O que ele quer vender são serviços, e o que quer comprar são ações. Já não é um capitalismo dirigido para a produção, mas para o produto, isto é, para a venda ou para o mercado. Por isso ele é essencialmente dispersivo, e a fábrica cedeu lugar à empresa (Deleuze, 1992:224).

Espaços exclusivos de produção não existem sem espaços dispersos de unidades domésticas. Nestas imperam métodos de organização de trabalho baseados na apropriação gratuita da força produtiva de trabalho social, no prolongamento da jornada e na divisão vertical e horizontal; ou seja, em métodos de trabalho intensivo. Nos espaços exclusivos da produção predominam processos de extração de mais-valia relativa, como a divisão parcelada do trabalho, a especialização de tarefas e ferramentas e, no caso da maquinaria, o emprego de máquinas ferramentas movidas por um motor e, mais tarde, de processos informatizados, caracterizando processos intensivos de investimentos de capital.

Por outro lado, quando as análises sobre a produção do espaço reconhecem a produção acessória de unidades domésticas no novo regime de acumulação flexível, não se menciona o papel do trabalho feminino nos novos processos de precarização da força de trabalho (subcontratação, emprego temporário, atividades autônomas, trabalho informal etc).

[...] podemos compreender o sistema putting-out como transição da moradia tradicional (unidade de produção), para a forma de moradia que prevalecerá nos países capitalistas industrializados até a década de 1930 (unidade 
de reprodução). No momento em que penetra no espaço doméstico, a lógica fabril modifica a percepção do trabalho de reprodução, tornando-o secundário frente à atividade geradora de renda. Quando, mais tarde, essa atividade é deslocada para o espaço da fábrica, a moradia parece tornar-se um oásis do não trabalho, embora o trabalho de reprodução continue sendo executado ali. O ônus dessa obliteração fica com as mulheres das classes não proprietárias, agora integradas ao mercado de trabalho $e$ ainda responsáveis pela manutenção da vida doméstica (Kapp; Lino, 2008:16).

A inclusão subordinada da economia doméstica à economia dominante e de base patriarcal sempre existiu, desde as corporações de ofício da Idade Média. Mas para além do predomínio do trabalho feminino, informal ou indigno nas unidades domésticas, outro trabalho material é desempenhado nesses espaços: a reprodução, essencial para liberar a força de trabalho masculina para o mercado, baseado no contrato formal entre trabalho e capital.

A discussão sobre as origens dos espaços de trabalho demonstrou que elas estão vinculadas à divisão sexual do trabalho, durante o desenvolvimento do capitalismo comercial no período entre os séculos XII e XVIII, quando as antigas unidades domésticas - indústrias domésticas rurais $-e$ as oficinas dos artesãos urbanos foram transformadas em empresas familiares pelo modo de produção putting-out. Com o advento desse sistema, a divisão sexual do trabalho permitiu liberar os indivíduos do sexo masculino para o desempenho de atividades produtivas, enquanto as tarefas domésticas ou mal pagas eram destinadas às mulheres. Essa foi a primeira condição social para posteriormente, na manufatura, possibilitar-se a existência de espaços exclusivos de produção. Os espaços nas antigas unidades domésticas não eram especializados, em função de relações sociais menos opressoras. O padrão doméstico de organização espacial, que abrigava atividades produtivas e reprodutivas sem distinção, advém do fato de os indivíduos contribuírem para a subsistência 
do grupo, mediante a autonomia coletiva na organização e no controle das atividades de produção e de consumo, e de mobilização de força re/produtiva de trabalho social.

Os espaços de corporação de ofício não devem ser considerados espaços de trabalho onde prevaleciam relações sociais igualitárias, a exemplo da representação dominante no senso comum técnico, presente até em autores marxistas. Isso somente ocorreu em áreas urbanas da Inglaterra medieval, nas quais as corporações pertenciam ao espaço de moradia $e$ as relações hierárquicas entre mestre e aprendiz eram de natureza linear. Em outras regiões da Europa, o padrão patriarcal de organização do trabalho $e$ do espaço predominava nas corporações de ofício, durante a Idade Média até a Idade Moderna, quando se privilegiavam as atividades produtivas em detrimento das reprodutivas. A divisão de trabalho por gênero expressava-se em normas rígidas que impediam as mulheres de aprender o ofício nas corporações, ou atribuíam a elas, de modo tácito ou explícito, as atividades da cadeia produtiva de menor valor agregado. Como, por exemplo, as relações desiguais entre mulheres fiadoras e homens tecelões em várias regiões da Europa, desde os séculos $\mathrm{XV}$ e $\mathrm{XVI}$, e entre as guildas de alfaiates e de costureiras na França do século XVII. A segregação do trabalho por gênero indica que a mão de obra feminina, acessória à economia dominante, já existia nas origens das corporações de ofício, o que precede em vários séculos a situação atual de alguns grupos de trabalho associado, cujo trabalho "indigno" feminino está submetido às normas do trabalho "digno" masculino, em uma relação de inclusão subordinada. O trabalho doméstico $e$ disperso dessas mulheres sustenta, ainda hoje, o trabalho de homens concentrados em espaços exclusivos para a produção.

No sistema de produção fabril, a divisão sexual do trabalho é expressa pelo emprego combinado de métodos de trabalho intensivo, a partir da exploração de grande quantidade de trabalhadores, denominada por Marx de cheap labour, e pelo emprego de processos intensivos de investimento de capital nas unidades fabris. Portanto, a relação entre o sistema de produção 
putting-out e o fabril (manufatura e maquinaria) não é uma questão de gradação tecnológica como os técnicos positivistas concebem, $e$ não somente uma questão de expropriação do saber operário mediante a organização racional do trabalho, como os marxistas esclarecem. Tal relação fundamenta-se em uma estratégia combinada de maior exploração da força de trabalho, baseada na divisão sexual do trabalho, além da divisão capitalista.

A estratégia combinada de exploração da força de trabalho pelo capital assume novo formato com o advento do sistema de produção automatizado na sociedade contemporânea. A tese da superação da "sociedade industrial", baseada no trabalho material, pela "sociedade informacional", centrada no trabalho imaterial, é facilmente questionável diante da estratégia combinada, pois até mesmo a substituição do paradigma da "máquina" pelo da "informação" não prescinde de os espaços de empresas - exclusivos de concepção e controle da produção dependerem de espaços dispersos de unidades domésticas ou semidomésticas. Assim, os trabalhadores anteriormente excluídos do trabalho assalariado e dos benefícios do Estado de Bem-Estar na sociedade industrial agora são incluídos de modo subordinado à sociedade informacional. É o caso dos trabalhadores que empreendem pequenos negócios como sistemas mais antigos de trabalho doméstico, artesanal, familiar (patriarcal) e paternalista, nos quais prevalecem o modo de produção putting-oute a gestão por metas. Mas diferentemente dos espaços de empresas, nas unidades dispersas, os instrumentos técnicos e organizacionais são de responsabilidade dos trabalhadores, que se tornam empreendedores em consonância com a ideologia neoliberal da meritocracia. A sobrevivência do capitalismo depende da perpetuação da divisão sexual do trabalho. O capitalismo contemporâneo mantém as distinções entre trabalho masculino $e$ feminino. Segundo seu interesse, mantém espaços de trabalho e de vida centralizados ou dispersos. 


\section{Referências bibliográficas}

Anderson, Perry. Passagens da Antiguidade ao Feudalismo. 3ed. São Paulo, Brasiliense, 1991. Tradução Beatriz Sidou. [1974]

ANTUNES, Ricardo. Os sentidos do trabalho: ensaio sobre a afirmação e a negação do trabalho. 2ed. 10. reimpr. rev. e ampl. São Paulo, Boitempo, 2009. [1999]

BRAVERMAN, Harry. Trabalho e Capital Monopolista. A Degradação do Trabalho no Século XX. Rio de Janeiro, Zahar, 1981. Tradução Nathanael C. Caixeto. [1974]

CROWSTON, Clare Haru. Women, gender and guilds in early modern Europe. In The return of the guilds. Conference of the Global Economic History Network. Utrecht, Utrecht University, October 2006.

DE MARE, Heide. Domesticity in Dispute. A reconsideration of Sources. In: CIERAAD, Irene (ed.). At home: an anthropology of domestic space. Syracuse University Press, New York, 1999, pp.13-29. Foreword by John Rennie Short.

DECCA, Edgar Salvadori de. O nascimento das fábricas. São Paulo, Brasiliense, 1982.

Deleuze, Gilles. Post-Scriptum sobre as sociedades de controle. In: DELEUZE, Gilles. Conversaçôes. 1972-1990. ed.34, Rio de Janeiro, 1992, pp.219-226.

Gorz, André. Divisão do Trabalho, Hierarquia e Luta de Classes. In: Marglin, S. et alii. Divisão Social do Trabalho, Ciência, Técnica e Modo de Produção Capitalista. Porto, Publicações Escorpião, 1996. [1974]

Gramsci, A. Cadernos do Cárcere. Americanismo e fordismo. (Cad. 22) Rio de Janeiro, Civilização Brasileira, 2001. [1934]

GRAY, Jane. Rural Industry and Uneven Development. The Significance of Gender in the Irish Linen Industry. Maynooth, The Journal of Peasant Studies 20 (4), 1993, pp.590-611.

GropIUS, Walter. Bahaus: novarquitetura. São Paulo, Perspectiva, 2004. [1937-52] 
HARVEY, David. Condição pós-moderna. 7.ed. São Paulo, Edições Loyola, 1998. [1989]

ILLICH, Ivan. Gender. New York, Pantheon Books, 1982.

KAPP, Silke; LINO, Sulamita Fonseca. Na Cozinha dos Modernos. Cadernos de Arquitetura e Urbanismo, vol.15, n¹6, Belo Horizonte, $1^{\circ}$ sem. 2008.

KRIEDTE, Peter; MediCK, Hans; SCHLUMBOHM, Jürgen. Industrialization before industrialization (Studies in modern capitalism). Cambridge, Cambridge University Press, 1981. Tradução Beate Schempp. [1977]

MARGLIN, Stephen. Origem e funções do parcelamento das tarefas. Para que servem os patrões? In: GoRz, André (org.). Crítica da divisão do trabalho. 3.ed. São Paulo, Martins Fontes, 1996, pp.37-77. [1973]

MARIUTTI, Eduardo Barros. Capital comercial autônomo: dinâmica e padrões de reprodução. Texto para Discussão n ${ }^{\circ} 214$, Campinas, IE/UNICAMP, dez. 2012.

MARX, Karl. Teorias da Mais Valia: história crítica do pensamento econômico. São Paulo: Bertrand Brasil, 1987. Volume 1. p. 384-406. [1863]

MARX, Karl Teorias da mais-valia. Rio de Janeiro: Bertrand Brasil, 1987. Volume I. [1857-8]

MarX, Karl. O Capital. Crítica da Economia Política. Livro Primeiro. O processo de produção do capital. Volume 1. 27.ed. Rio de Janeiro, Civilização Brasileira, 2010. Tradução de Reginaldo Sant'Anna. Título original: Das Kapital - Kritik der Politischen Ökonomie Buch I: Des Produktions-process des Kapitals. [1859]

MEDICK, Hans. The proto-industrial family economy. In: KRIEDTE, Peter, MEDICK, Hans; SCHLUMBOHM, Jürgen. Industrialization before industrialization (Studies in modern capitalism). Cambridge: Cambridge University Press, 1981, pp.38-73. Translated by Beate Schempp. [1977]

MENDELS, Franklin F. Proto-industrialization: The First Phase of the Industrialization Process". The Journal of Economic History, 32/1, The Tasks of Economic History, 1972, pp.241-261. 
MoraEs NeTO, Benedito Rodrigues de. Maquinaria, taylorismo $e$ fordismo: a reinvenção da manufatura. Revista de Administração de Empresas, 26(4), Rio de Janeiro, out/dez 1986, pp.31-34.

MotA, Nelson. A Arquitectura do Quotidiano. Público e Privado no Espaço Doméstico da Burguesia Portuense no Final do Século XIX. Coimbra, Edarq, 2010.

MumForD, Lewis. A cidade na história: suas origens, transformações e perspectivas. 4.ed. São Paulo, Martins Fontes, 1998, pp.307-342. Tradução de Neil R. da Silva. [1961]

Olgivie, Sheilagh C.; Cerman, Markus (ed.) Proto-industrialization: The First Phase of the Industrialization Process. The Journal of Economic History, 32/1, The Tasks of Economic History. Cambridge, University of Cambridge, 1996, pp.241-261. [1994]

OlgIVIE, Sheilagh. Guilds, efficiency, and social capital: evidence from german proto-industry. CESIFO working. Paper $n^{\circ} .820$. Category 10: empirical and theoretical methods. Cambridge, University of Cambridge, dezembro 2002, pp.1-33.

OLGIVIE, Sheilagh. Can we rehabilitate the guilds? A sceptical reappraisal. Cambridge, University of Cambridge, 2007.

PIGNON, D.; QUERZOLA, J. Ditadura e democracia na produção. In: GORZ, A. Crítica da divisão do trabalho. São Paulo: Martins Fontes, 1989, p. 91-129.

SAlerno, Mário Sérgio. Projeto de organizações integradas e flexíveis. São Paulo, Atlas. Cap. 5, 1999.

TILLY, Louise A.; SCOTT, Joan W. Womem, work, and family. New York, Holt, Rinehart and Winston, Parte 1, 1987. [1978]

Weber, Max. A ética protestante e o espírito do capitalismo. São Paulo, Martin Claret, 2001. Tradução de Pietro Nassetti. [1904-5] Versão inglesa de Talcott Parsons. Original alemão. 